\section{Co-Labora Incubadora de Empreendimentos Solidários: Experiência de Economia Solidária em Projetos de Extensão Universitária em Ribeirão Preto}

\author{
Co-Labora Incubator of Solidary Economic Enterprises: \\ Experience of Solidary Economic on University Extension \\ Projects in Ribeirão Preto
}

\section{RESUMO}

Apesar da ausência de políticas públicas no município que incentivassem a formação de empreendimentos econômicos solidários (EES) e que fortalecessem a articulação desses, havia um grupo de professores que atuavam na sociedade no combate à extrema pobreza com projetos de geração de renda. As experiências individuais realizadas em cada área profissional careciam de articulação para alavancar o processo de incubação. Em dezembro de 2013, por meio da Chamada no 89/2013 MCTI-SECIS-MTE-SENAES-CNPq, foi fundada a Co-Labora, Incubadora de empreendimentos solidários da USP, campus Ribeirão Preto. Assim, formou-se uma equipe de pesquisa e extensão multidisciplinar com professores, alunos (graduação e pós-graduação) das áreas de terapia ocupacional, economia, administração, direito e psicologia para desenvolver serviços tecnológicos às EES. O método de incubação consiste em: formação semanal em economia solidária; visita dos estagiários e supervisor semanalmente aos grupos; reuniões semanais dos supervisores e estagiários; reuniões quinzenais da equipe de docentes e coordenadores; e capacitações específicas com profissionais externos, dada a demanda. A partir desse método temos conseguido fortalecer as cooperativas existentes, incentivar a formação de novas cooperativas, disseminar o conceito de economia solidária nos empreendedores de bairros e apresentar essas iniciativas baseadas em economia solidária para a Prefeitura e várias secretarias públicas.

Palavras-chave: Economia Solidária. Incubadora. Extensão Universitária.

\section{ABSTRACT}

Despite the absence of public politics in the county, that would encourage formation of solidary economic enterprises (SEEs) and that would strengthen the articulation of SEEs, there were a group of teachers who worked in society to fight extreme poverty with income-generating projects. The individual experiences in each occupational
Perla Calil

Pongeluppe Wadhy

ReBehy, Daniel

Yacoub Bellissimo

Universidade de São Paulo.Faculdade de Economia, Administração e Contabilidade de Ribeirão Preto, São Paulo, Brasil

SaMANTHA GORdo SANDRIN, REgINA Célia Fiorati, Regina Yoneko Dakuzaku CARRETTA

Universidade de São Paulo.Faculdade de Medicina de Ribeirão Preto, São Paulo, Brasil 
area lacked coordination to leverage the incubation process. In December 2013, through the Call No. 89/2013 MCTI-SECIS-MTE-SENAES-CNPq, was founded Co-Labora, an Incubator of solidarity enterprises at USP, Ribeirão Preto campus. Thus, a team of multidisciplinary research and extension faculty, counting with teachers and students (undergraduate and graduate) in the areas of occupational therapy, economics, administration, law and psychology was formed to develop technological services to SEEs. The incubation method consists of: Weekly training in economic solidarity; visit trainees and supervisor weekly to groups; weekly meetings of supervisors and trainees; fortnightly team meetings teachers and coordinators; and specific skills training with external professionals, if there is demand. From this method, we have been able to strengthen existing cooperatives, encourage the formation of new cooperatives, spread the concept of solidarity economy entrepreneurs in neighborhoods and present those initiatives based on solidarity economy philosophy for the City Hall and for various departments of government.

Keywords: Solidarity Economy. Incubator. University Extension.

\section{INTRODUÇÃO}

\section{O objetivo deste trabalho é descrever a experiência da Co-Labora - Incubadora} Tecnológica de Empreendimentos Solidários (ITES), junto a grupos atendidos: cooperativa de agentes ambientais de resíduos sólidos, grupo de costureiras, produtores de horti-fruti orgânicos de um assentamento, pessoas em vulnerabilidade atendidas pelo programa do governo federal e municipal e, empreendedores locais de um bairro. Essa ação foi incentivada pelo edital do CNPq, por meio do Ministério do Trabalho e Emprego (MTE) e Secretaria Nacional de Economia Solidária (SENAES) em dezembro de 2013.

A metodologia de incubação proposta considerou a experiência de cada membro da equipe no acompanhamento e desenvolvimento de ações junto a grupos, sempre tendo a autogestão e emancipação social como princípios, além de considerar a experiência do Numi-Ecosol/UFSCar, a incubadora que nos apoia no presente edital. Também se considera importante a articulação dos vários atores envolvidos, fortalecendo a interdisciplinaridade e ações intersetoriais.

Os EES estão presentes em todas as regiões do Brasil, totalizando 21.859 empreendimentos em 2.933 municípios, sendo distribuídos entre as regiões da seguinte forma: Nordeste $-43,5 \%$, Sudeste $-18 \%$, Sul $-16,5 \%$, Norte $-12 \%$ e Centro-Oeste $-10 \%$ [8]

Contudo, estudos apontam dificuldades vivenciadas por esses trabalhadores nos seus processos de produção e gestão, o que resulta em uma inconstância no que se refere à renda, aos processos de geração de tecnologias sociais e políticas públicas que atuem no desenvolvimento sócio econômico dos empreendimentos bem como o fracasso e dissolução de muitos deles. Assim, um dos grandes desafios é atingir a condição de autossuficiência desses empreendimentos. No sentido de colaborar com a viabilização socioeconômica dos EES, constituem-se experiências de incubadoras, muitas vezes vinculadas às Universidades, conforme caso da Co-Labora.

O município de Ribeirão Preto não possuía incubadora de apoio a empreendimentos 
econômicos solidários até dezembro de 2013, no entanto há algumas iniciativas dispersas públicas (com algumas ações específicas de docentes da Universidade de São Paulo) e privadas (algumas associações de bairros ou profissionais). De um lado Ribeirão Preto apresenta 604.682 habitantes, sendo $52 \%$ mulheres e $46 \%$ em idade economicamente ativa (até 60 anos), uma composição do Produto Interno Bruto originária $80 \%$ de serviços e $19 \%$ da indústria [6]. Por outro lado, a proporção da renda apropriada pelos $20 \%$ mais ricos era de 66,2\% em 1991, e aumentou para 68,1\% em 2000. Esse é um número bastante elevado e confirma a apresentação de taxas de desemprego elevadas entre os intervalos de renda com menor remuneração.

De acordo com o Índice Paulista de Responsabilidade Social, Ribeirão Preto está classificado no Grupo 2, isso significa localidade com bom nível de riqueza que não se reflete nos indicadores sociais, considerando-se principalmente indicadores de longevidade e escolaridade [10]. Por outro lado, o Índice Paulista de Vulnerabilidade Social, feito com base no censo 2000 , revela $27 \%$ da população entre vulnerabilidades média à muito alta, conforme Gráfico 1.

Gráfico 1 - Distribuição da População, segundo Grupos do Índice Paulista de Vulnerabilidade Social - IPVS, comparando Estado de São Paulo e município de Ribeirão Preto [5].

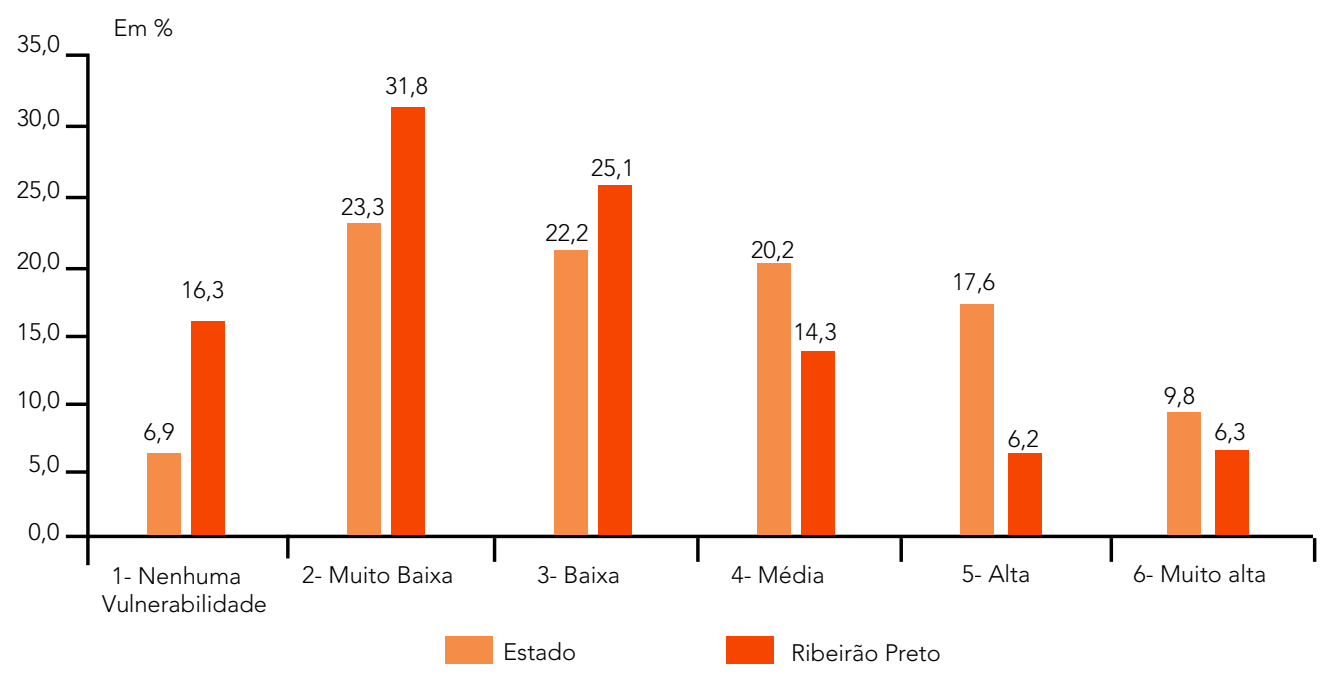

A partir dos dados da Fundação Seade é possível verificar as características de cada grupo, conforme a Tabela 1 . 
Tabela 1 - Indicadores que compõem o Índice Paulista de Vulnerabilidade Social - IPVS de Ribeirão Preto [5].

\begin{tabular}{|c|c|c|c|c|c|c|c|}
\hline \multirow[b]{2}{*}{ INDICADORES } & \multicolumn{6}{|c|}{ ÍNDICE PAULISTA DE VULNERABILIDADE SOCIAL } & \multirow[b]{2}{*}{ TOTAL } \\
\hline & $\begin{array}{l}\text { 1- NENHUMA } \\
\text { VULNERABILIDADE }\end{array}$ & $\begin{array}{l}2- \\
\text { MUITO } \\
\text { BAIXA }\end{array}$ & 3- BAIXA & 4- MÉDIA & 5- ALTA & $\begin{array}{l}\text { 6- } \\
\text { MUITO } \\
\text { ALTA }\end{array}$ & \\
\hline População Total & 82.179 & 160.397 & 126.413 & 71.836 & 31.481 & 31.773 & 504.079 \\
\hline Percentual da População & 16,3 & 31,8 & 25,1 & 14,3 & 6,2 & 6,3 & 100,0 \\
\hline Domicílios Particulares & 27.069 & 47.645 & 35.060 & 19.074 & 8.484 & 7.732 & 145.064 \\
\hline $\begin{array}{c}\text { Tamanho médio do Domicílio } \\
\text { (em pessoas) }\end{array}$ & 3,0 & 3,4 & 3,6 & 3,8 & 3,7 & 4,0 & 3,5 \\
\hline $\begin{array}{c}\text { Responsáveis pelo Domicílio } \\
\text { Alfabetizados (\%) }\end{array}$ & 99,4 & 96,5 & 95,5 & 93,7 & 89,17 & 84,1 & 95,4 \\
\hline $\begin{array}{c}\text { Responsáveis pelo Domicílio } \\
\text { com Ensino Fundamental } \\
\text { Completo (\%) }\end{array}$ & 86,7 & 50,0 & 47,6 & 37,1 & 26,6 & 18,4 & 51,5 \\
\hline $\begin{array}{l}\text { Anos Médios de Ensino do } \\
\text { Responsável pelo Domicílio }\end{array}$ & 12,3 & 7,5 & 7,2 & 6,1 & 5,2 & 4,3 & 7,8 \\
\hline $\begin{array}{l}\text { Rendimento Nominal Médio } \\
\text { do Responsável pelo Domicílio } \\
\text { (em reais de julho de 2000) }\end{array}$ & 2.906 & 985 & 912 & 593 & 561 & 344 & 1.215 \\
\hline $\begin{array}{c}\text { Responsáveis com Renda de } \\
\text { até } 3 \text { salários mínimos (\%) }\end{array}$ & 9,1 & 33,9 & 37,1 & 49,7 & 54,7 & 75,9 & 35,6 \\
\hline $\begin{array}{l}\text { Responsáveis com idade entre } \\
10 \text { e } 29 \text { anos (\%) }\end{array}$ & 12,6 & 9,1 & 13,9 & 21,3 & 12,9 & 27,4 & 13,7 \\
\hline $\begin{array}{c}\text { idade média dos responsáveis } \\
\text { pelo Domicílio (em anos) }\end{array}$ & 47 & 50 & 44 & 40 & 47 & 39 & 46 \\
\hline $\begin{array}{c}\text { Mulheres Responsáveis pelo } \\
\text { Domicílio (\%) }\end{array}$ & 28,3 & 29,3 & 24,9 & 21,7 & 24,5 & 21,1 & 26,3 \\
\hline $\begin{array}{c}\text { Crianças de } 0 \text { a } 4 \text { anos no Total } \\
\text { de residentes (\%) }\end{array}$ & 5,3 & 5,6 & 8,0 & 11,1 & 7,9 & 13,8 & 7,6 \\
\hline
\end{tabular}

Em 2003, o Ministério do Trabalho e Emprego do Brasil criou a Secretaria Nacional de Economia Solidária - SENAES para cumprir o objetivo a seguir descrito e a Prefeitura Municipal de Ribeirão Preto até o momento não apresentou no Plano Municipal ações para estimular a criação de empreendimentos econômicos solidários.

Em consonância com a missão do Ministério do Trabalho e Emprego, tem o objetivo viabilizar e coordenar atividades de apoio à Economia Solidária em todo o território nacional, visando à geração de trabalho e renda, à inclusão social e à promoção do desenvolvimento justo e solidário.[11]

Neste contexto nasceu a Co-Labora, uma nova incubadora de empreendimentos econômicos solidários na Universidade de São Paulo, campus de Ribeirão Preto, para apoiar o desenvolvimento de EES. Apesar da ausência de políticas públicas 
municipais que incentivem a formação de EES e que fortaleçam a articulação dessas, há um grupo de professores que, na época, desenvolviam ações isoladas na comunidade para combate à extrema pobreza por meio de projetos de geração de renda. Tais experiências realizadas em âmbito mais específico em cada área profissional, por mais que vislumbrando e desenvolvendo esforços no sentido interdisciplinar e mesmo intersetorial, careciam de uma articulação mais significativa para alavancar um processo de incubação mais efetivo junto a esses empreendimentos. Assim, essas pessoas, agora constituindo uma equipe de pesquisa e extensão multidisciplinar formada por técnicos, professores, alunos de graduação e pós-graduação das áreas de terapia ocupacional, economia, administração de empresas, direito, psicologia e sociologia se uniram para desenvolver serviços tecnológicos voltados às necessidades organizacionais dos EES.

\section{MATERIAIS E MÉTODOS}

Esse relato de experiência é descritivo, apontando os avanços das experiências obtidas até o momento por uma incubadora universitária.

\section{DESCRIÇÃO DOS RESULTADOS}

A descrição tem como ponto de partida a metodologia proposta pela tutora Incubadora Numi-Ecosol da UFSCar e a incorporação e adequação das nossas ações conforme as demandas dos grupos.

A metodologia de incubação da Co-Labora compreende três fases: pré-incubação, incubação e acompanhamento. A pré-incubação consiste na identificação de uma atividade produtiva comum entre membros de grupos nascentes, apresentação do conceito de economia solidária como base para formação de organizações coletivas, e análise de viabilidade econômica e social do negócio. Durante essa etapa são feitas reuniões semanais com as pessoas interessadas.

A incubação acontece com dois tipos de intervenções: encontros semanais e assessorias. Os encontros são presenciais e discutem-se aspectos de economia solidária; relacionamento entre os membros do grupo; empoderamento dos mesmos; identificação de potencialidades e fragilidades da organização; e utilização de conhecimentos específicos de terapia ocupacional orientados para a emancipação e autonomia de pessoas que, por razões ligadas à problemática específica, físicas, sensoriais, mentais, psicológicas e/ou sociais apresentam dificuldades na inserção e participação social. Os serviços oferecidos de assessoria são: desenvolvimento de estratégias coletivas de comercialização; captação de recursos públicos e privados para financiamento das atividades sob a forma de microcrédito ou incentivos governamentais; organização do processo de formação de grupos; gerenciamento dos negócios da forma autogestionária; incorporação dos direitos socioambientais no gerenciamento dos ESS e nos produtos e serviços comercializados por essas; conhecimento das modalidades jurídicas para formalização do empreendimento (cooperativa, associação, 
rede); conhecimento dos regimes fiscais para apuração dos tributos/impostos devidos; conhecimentos dos direitos e deveres previdenciários com objetivo de garantir qualidade de vida também na fase não operativa; direitos humanos e constitucionais; cidadania; qualidade de vida no trabalho; e cuidados com higiene pessoal. Essas atividades de assessorias são realizadas fora dos encontros presenciais, pois exige que nossa equipe pesquise sobre o assunto, entenda a cadeia produtiva em que estão inseridos e retornem outro dia da semana para validar e assessorá-los na implementação. Assim eles se apropriam do conhecimento para realizá-lo de maneira autônoma, na próxima oportunidade.

E após cerca de dois anos de incubação (avaliado em cada caso), a organização passa para o período de acompanhamento, onde são propostos alguns indicadores qualitativos e quantitativos que apontam o progresso na consolidação em rede de economia solidária, na inserção de uma cadeia produtiva existente e no relacionamento com o poder público.

O objetivo da incubadora é proporcionar sustentabilidade aos EES, tendo em vista que, quando esses atuam sem apoio, a maioria deles apresenta dificuldades no alinhamento do grupo, nas discussões de interesses individuais, na dificuldade de colocação dos produtos no mercado consumidor, na arrecadação dos tributos devidos, no atendimento das necessidades do grupo frente às individuais, entre outros. Dado a fase embrionária em que se encontra a economia solidária no município de Ribeirão Preto, essa sustentabilidade seria alcançada por meio de ações coletivas em três níveis: ações da Incubadora, descritas no parágrafo anterior, de forma a garantir, em determinado momento, a autonomia organizacional e a viabilidade econômico-financeira; apoiadores da sociedade (conselhos profissionais, vereadores, especialistas na área, associações de bairros); e políticas públicas que incentivem e fortaleçam a economia solidária.

As metodologias participativas de intervenção vêm se demonstrando um bom caminho de intervenção junto aos grupos sociais, inclusive aqueles com finalidade de geração de trabalho e renda. Nessa perspectiva, as ações se realizam em grupos, com o intuito de ultrapassar a transmissão de conhecimentos técnicos, de buscar a constituição de espaços facilitadores da reflexão e de tomada de consciência da forma como se organizam cotidianamente. Pauta-se na compreensão de que os trabalhos realizados em grupos apresentam maiores possibilidades de êxito no que se refere à adoção de novas atitudes e práticas [12].

A partir desse mesmo método de incubação tem-se obtido os resultados descritos a seguir.

\section{Cooperativa de catadores de resíduos sólidos}

A região dos bairros Branca Salles, Monte Alegre e Parque Ribeirão, dentre outros bairros da região Oeste de Ribeirão Preto é caracterizada como zona de vulnerabilidade social na cidade, apresentando altos índices de catadores individuais de materiais recicláveis pelas ruas. A Cooperativa foi fundada em 2005, mas passou a ser atendida 
pela Co-Labora ITES no início de 2014. Na fase de incubação passou-se a visitar este grupo duas vezes por semana - uma para realização de formação em aspectos diversos demandados pelo grupo em conformidade com a economia solidária; outra para acompanhamento e assessoria nas necessidades correntes da cooperativa, sejam elas jurídicas, de gestão ou de coesão no grupo. No início da atuação da Co-Labora, em 2014, percebeu-se que o grupo apresentava ainda uma importante dependência em relação aos seus apoiadores externos tanto quanto do poder público - representado principalmente pela secretaria de assistência social. O grupo não apresentava uma formação relevante em Economia Solidária e os elementos adjuntos - como a autonomia, empoderamento, integração e coesão do grupo, autogestão, controle e organização administrativa, dentre outros. Atualmente a incubação da Co-Labora procura desenvolver uma cultura influenciada pelos princípios da economia solidária, bem como, valores e práticas vinculadas a essa filosofia, tais como: autonomia do grupo, autogestão, horizontalidade e democracia na gestão, entre outros.

\section{Projeto Renascer das Águas do Aquífero Guarani}

O projeto, constituído por membros do Assentamento Mário Lago (MST), em Ribeirão Preto-SP, no bairro Jardim Mário Lago, Zona Norte da cidade, visa à recuperação do solo e da reserva de água da região, desgastado pela ação erosiva da monocultura mantida por muitos anos na região.

Uma das maneiras de atuar por tal recuperação ambiental e também pela subsistência alimentar e financeira dos assentados (agricultores familiares) é realizar o sistema agroflorestal (SAF) nos lotes. Um dos objetivos do projeto é realizar tal fortalecimento da produção agroflorestal, através da capacitação e apoio a 80 agricultores. A meta é a conversão de 60 hectares de terra em espaços que aliam a produção de alimentos à conservação ambiental.

Com mais de 30 anos de história, o Movimento dos Trabalhadores Sem Terra tem larga experiência no que diz respeito a trabalhos em grupo e a participação popular na construção de projetos visando à luta pela melhoria nas condições de vida de sua população.

Uma das premissas do projeto é a participação dos consumidores de forma ativa em busca dos produtos provenientes da agrofloresta, inclusive realizando visitas e reuniões no assentamento, caminhando para um consumo consciente e uma economia solidária (os membros do projeto têm consciência de seus preceitos).

Esse projeto tem várias frentes e grupos de trabalho - Implantação e Produção, Administrativo-Financeiro, Divulgação, Comercialização e outras - assim, o papel da Incubadora tem sido paulatinamente se inserir nas discussões realizadas entre seus membros (reuniões coletivas semanais de planejamento), com a consciência humilde de que necessita aprender com tal movimento, além de realizar intervenções de assessoramento conforme demanda. A ação da Incubadora Co-Labora tem sido proposta para o apoio técnico para a comercialização dos produtos, a saber: busca por orçamentos, cotações de preços, material para comunicação e divulgação pública. 
No bairro Monte Alegre, próxima a campus USP de Ribeirão Preto, situa-se a COVIMAI, a Associação de Moradores dos Bairros da Vila Monte Alegre e Alto do Ipiranga. A associação, há mais de 30 anos, defende os interesses da comunidade perante o poder público, tanto quanto organiza projetos de cunho transformador da realidade local. Um dos projetos, recentemente sem atividade, era de alfabetização, realizada pela organização Alfasol, nacionalmente conhecida.

Inicialmente, houve a intenção manifesta por uma pessoa conhecida dos diretores da associação, de que fosse formado um grupo de geração de renda utilizando-se os espaços e as influências da associação. Tal grupo deveria se organizar em torno de preceitos de capacitação e cooperação, e se daria com microempreendedores individuais (MEI), mapeados na região com principal influência na área de alimentação. A ação da Incubadora Co-Labora tem se desenvolvido na perspectiva de trabalhar a formação e coesão grupal e os princípios da economia solidária para a gestão de empreendimentos de geração de renda local.

\section{Projeto Talentos}

O Projeto Talentos foi inaugurado através de uma iniciativa apoiada pela Associação Programa de Mãos Estendidas (de direito privado, sem fins econômicos), buscando capacitar mulheres, jovens e adultas, para a geração de renda, no segmento de corte e costura. $\mathrm{O}$ foco deste projeto englobou mulheres sem ofício e que tinham interesse no aprendizado de uma nova atividade, com objetivo final de geração de renda.

Das doze mulheres participantes inicialmente, apenas seis deram seguimento ao grupo, produzindo produtos como: bolsas, carteiras, roupas, jogo americano, entre outros, sendo os mesmos vendidos em eventos beneficentes ou mesmo em bazares realizados no próprio espaço do Programa de Mãos Estendidas e do Projeto Talentos.

Após a finalização do curso, o grupo contou com a presença de alguns voluntários, atuando como "professores" do grupo, com intenção de acompanhá-lo na produção, ensinando novas técnicas de costura. No entanto, mesmo com esse acompanhamento, a dificuldade em relação à comercialização de seus produtos permaneceu, além de algumas outras questões mais relacionadas com a dinâmica do grupo propriamente dita.

Dessa forma, em 2014, o grupo passou a ser acompanhado pela Incubadora Co-Labora, que se apresentou com o objetivo de auxiliar na organização da produção, comercialização e dinâmica interna do grupo. A incubação da Co-Labora se desenvolve no sentido de apoiar a autonomia do grupo, o fortalecimento da coesão grupal, as decisões que envolvem a produção e as formas de comercialização e a gestão da renda produzida.

\footnotetext{
* A Alfabetização Solidária (AlfaSol) é uma entidade da sociedade civil criada em 1996 com a missão de disseminar e fortalecer o desenvolvimento social por meio de práticas educativas sustentáveis. Com um modelo simples de alfabetização inicial, inovador e de baixo custo. Baseada no sistema de parcerias com os diversos setores da sociedade, a Organização trabalha pela redução dos altos índices de analfabetismo no país. Até o final de 2010, a AlfaSol registrou o atendimento de 5,5 milhões de alunos em 2.205 municípios brasileiros, além da capacitação de 257 mil alfabetizadores. Um trabalho que, até 2010, contou com a parceria de 162 empresas e 41 Instituições de Ensino Superior (IES).
} 
O CAPS AD é um serviço que oferece atendimento especializado para pessoas em uso abusivo de álcool e outras drogas, por equipe multidisciplinar. O objetivo principal do CAPS AD é oferecer atendimento à população, contando com atividades terapêuticas e preventivas, atenção ambulatorial diária, atendimento individual, atendimentos em grupo ou oficinas terapêuticas, visitas domiciliares, condições para o repouso dos usuários, desintoxicação ambulatorial e reabilitação psicossocial. Dentre os campos profissionais componentes da equipe multidisciplinar, está a Terapia Ocupacional, que realiza trabalhos de grupo e em parceria com outros profissionais desta equipe.

A partir de 2014, o Curso de Terapia Ocupacional da FMRP-USP, integrando a Co-Labora ITES e através das atividades de estágio profissionalizante do curso no CAPS AD apresentou a proposta de formação de um grupo, de geração de renda. Sendo assim, a divulgação de tal iniciativa se deu pelo estagiário da Terapia Ocupacional, convidando os usuários do serviço para uma reunião, na qual foi apresentada a proposta e sobre a filosofia da economia solidária.

Neste momento, um grupo de seis usuários mostrou-se interessado na proposta. Assim, começaram a discussão e experimentação de atividades, com base no histórico de ocupações dos usuários, com objetivo final de definir qual seria o ofício do grupo. Eles escolheram uma cooperativa de serviços, já que muitos tinham experiências anteriores na área de construção civil, jardinagem, pintura, entre outros.

Assim, os encontros tem sido para criação de um regimento interno, divulgação da "cooperativa" e compra de materiais para início dos serviços. Para essa aquisição está sendo elaborado um projeto de captação de recursos para compra de materiais para que os usuários possam começar a prestação de serviços.

\section{DISCUSSÃO DOS RESULTADOS}

As metodologias de incubação utilizadas pela Co-Labora tem procurado abarcar aquelas preconizadas pela filosofia da economia solidária guiando-se pelos valores da autogestão, solidariedade, cooperação, democracia, autonomia e empoderamento, participação e aumento da coesão social e comunitária para fortalecimento de redes sociais de suporte locais e nos territórios envolvidos. Assim, a incubadora não tem focado suas ações apenas na geração de renda, mas também na geração de capital social para os grupos envolvidos, especialmente no que diz respeito à autonomia dos grupos e das pessoas que os compõem na perspectiva de poderem tomar as decisões necessárias à sua manutenção e desenvolvimento sem coerções de setores dominantes, chefias ou patronatos, assim como tem procurado empoderar os grupos e pessoas, no sentido de fazer com que se conscientizem de que podem e devem lutar por direitos sociais e políticos, tomar parte nas deliberações políticas e econômicas da sociedade municipal e em outras esferas. 
Como a Co-Labora é nova e a comunidade não a conhecia, os grupos atendidos foram convidados a receberem esse apoio por meio do processo de incubação. Em quatro deles os professores atuavam anteriormente, mas com outra forma de apoio, normalmente com projetos de extensão restritos às Unidades e um deles foi estimulado a partir de um novo contato.

Tabela 2 - Tempo de vida dos incubados

\begin{tabular}{|c|c|}
\hline INCUBADOS & ESTÁGIO DE VIDA \\
\hline COOPERATIVA MÃOS DADAS & $\begin{array}{l}\text { Foi criada em } 2005 \text { a partir de um grupo da assistência } \\
\text { social, atentos às necessidades dos catadores, realizou } \\
\text { um processo de organização unindo-os pelo propósito } \\
\text { de atingirem melhores condições em torno de uma } \\
\text { cooperativa. }\end{array}$ \\
\hline $\begin{array}{l}\text { PROJETO "RENASCER DAS } \\
\text { ÁGUAS DO AQUÍFERO } \\
\text { GUARANI" }\end{array}$ & $\begin{array}{l}\text { É um dos assentamentos do Movimento dos Sem Terra } \\
\text { (MST) na cidade de Ribeirão Preto, ocupado em } 2003 .\end{array}$ \\
\hline $\begin{array}{l}\text { REDE DE EMPREENDEDORISMO } \\
\text { SOLIDÁRIO DO MONTE ALEGRE }\end{array}$ & $\begin{array}{l}\text { Estágio nascente, ainda não constituído como grupo, } \\
\text { mas recebendo curso de formação em economia } \\
\text { solidária desde maio de } 2014 \text {. }\end{array}$ \\
\hline PROJETO TALENTOS & $\begin{array}{l}\text { O Projeto Talentos foi inaugurado em } 2012 \text { a partir } \\
\text { de uma iniciativa apoiada pela "Associação Programa } \\
\text { de Mãos Estendidas" (de direito privado, sem fins } \\
\text { econômicos), buscando capacitar mulheres jovens e } \\
\text { adultas para geração de renda, no segmento de corte } \\
\text { e costura. }\end{array}$ \\
\hline $\begin{array}{l}\text { CAPS AD (CENTRO DE ATENÇÃO } \\
\text { PSICOSSOCIAL A USUÁRIOS DE } \\
\text { ÁLCOOL E OUTRAS DROGAS) }\end{array}$ & $\begin{array}{l}\text { Esse grupo foi constituído em abril de 2014, a partir } \\
\text { das iniciativas de formação em economia solidária da } \\
\text { Incubadora Co-Labora. }\end{array}$ \\
\hline
\end{tabular}

Assim como se pode observar na Tabela 2, a rede de empreendedorismo solidário do Monte Alegre é o novo integrante. Já o CAPS AD, apesar do grupo de geração de renda ter surgido em maio de 2014, as professoras da terapia ocupacional trabalham com a Secretária de Saúde desde o $2^{\circ}$ semestre de 2013. Os grupos estabelecidos há mais tempo, apesar de realizarem várias atividades de maneira independente, demandam a participação da incubadora em pontos específicos, como negociação de contratos, parcerias com o poder público, apoio na captação de recursos. Por outro lado trazem a rigidez dos antigos processos. 
Tabela 3 - Etapas do processo da incubação

\begin{tabular}{ll}
\hline \multicolumn{1}{c}{ MÉTODO DE INCUBAÇÃO } & \multicolumn{1}{c}{ INCUBADOS } \\
\hline PRÉ-INCUBAÇÃO & $\begin{array}{l}\text { Rede de Empreendedorismo Solidário do Monte Alegre, } \\
\text { CAPS AD (Centro de Atenção Psicossocial a Usuários de } \\
\text { álcool e outras drogas) }\end{array}$ \\
\hline INCUBAÇÃO & $\begin{array}{l}\text { Cooperativa Mãos Dadas, Projeto Talentos, Projeto } \\
\text { Renascer das Águas do Aquífero Guarani }\end{array}$ \\
\hline ACOMPANHAMENTO & -
\end{tabular}

A pré-incubação é um estágio delicado onde a incorreta identificação de oportunidade de trabalho ou fraca atuação do interventor pode levar a não adesão do grupo e à insustentabilidade do negócio. $\mathrm{O}$ tempo demandado pelo grupo é menor, o que significa um período maior para concretização. Já os grupos que estão em processo de incubação, as formações semanais e assessorias, aumentam o vínculo, o que também proporciona maiores avanços.

\section{Outros Apoiadores: Poder Público e Privado}

Os grupos são atendidos pela incubadora, mas também contam com apoio de outros agentes, públicos e privados. Ao observar a Tabela 4, é possível concluir que dois deles são projetos relacionados com as secretarias do municípios (Cooperativa Mãos Dadas é um projeto da assistência social, e CAPS AD está sendo desenvolvido dentro dos atendimentos da secretaria da Saúde). O Assentamento tem apoio do Governo Federal, mas esse não tem atuação local e nem interferência no nosso processo de incubação, diferentemente da Mãos Dadas que além de ser um projeto da assistência municipal conta com apoio de organizações privadas (Coca-Cola, Instituto Brasileiro de Reciclagem do Pão de Açúcar) e outros atores institucionais. 
Tabela 4 - Apoiadores dos grupos atendidos.

\begin{tabular}{|c|c|}
\hline INCUBADOS & APOIADORES \\
\hline COOPERATIVA MÃOS DADAS & $\begin{array}{l}\text { A USP já há alguns anos desempenha papel de apoio à } \\
\text { cooperativa, seja através do USP Recicla, atividades de } \\
\text { assessoria jurídica do NAJURP (Núcleo de Assessoria } \\
\text { Jurídica/USP), e atividades de assessoria em gestão do PICE } \\
\text { Cooperativas (Programa de Capacitação Empreendedora). } \\
\text { Ela é um projeto da Secretária da Assistência Social, portanto } \\
\text { apoiado com cestas básicas, transporte dos membros, } \\
\text { pagamento de água, luz, telefone e prédio emprestado. } \\
\text { Há um grupo gestor que também o apoia, formado por atores } \\
\text { públicos (Ministério Público, Defensoria) e privados (Coca- } \\
\text { Cola, Banco do Brasil, e Faculdades Moura Lacerda). }\end{array}$ \\
\hline $\begin{array}{l}\text { PROJETO "RENASCER DAS } \\
\text { ÁGUAS DO AQUÍFERO } \\
\text { GUARANI" }\end{array}$ & $\begin{array}{l}\text { Idealizado e realizado como uma parceria entre o Centro de } \\
\text { Formação Sócio-Agrícola Dom Helder Câmara e a Secretaria } \\
\text { Estadual do Meio Ambiente, o projeto pretende comercializar } \\
400 \text { toneladas de produtos agroflorestais em dois anos. } \\
\text { Recebe também apoio federal. }\end{array}$ \\
\hline $\begin{array}{l}\text { REDE DE } \\
\text { EMPREENDEDORISMO } \\
\text { SOLIDÁRIO DO MONTE } \\
\text { ALEGRE }\end{array}$ & $\begin{array}{l}\text { Tem no momento apoio somente da COVIMAI - } \\
\text { Associação de Moradores dos Bairros da Vila Monte Alegre } \\
\text { e Alto do Ipiranga. }\end{array}$ \\
\hline
\end{tabular}

Esse projeto foi cadastrado como um DRS (Desenvolvimento Regional Sustentável) do Banco do Brasil, assim, recebeu curso de corte e costura oferecido em uma sala do Programa Mãos Estendidas, e maquinário doado ao grupo pela Fundação Banco do Brasil.

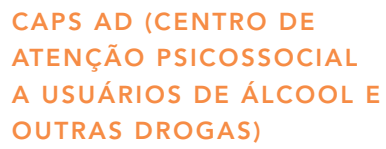

CAPS AD (CENTRO DE ATENÇÃO PSICOSSOCIAL A USUÁRIOS DE ÁLCOOL E OUTRAS DROGAS)

Recebe apoio da equipe de profissionais do CAPS AD que disponibilizam horário entre os atendimentos terapêuticos priorizando toda ação que faça inclusão social pelo trabalho e da administração que disponibiliza o espaço físico para as reuniões e assembléias.

\section{Ações Realizadas e Resultados Alcançados}

Em relação à Cooperativa Mãos Dadas, a incubação realizada pela Co-Labora objetiva resgatar os elementos fundamentais para a sustentabilidade no longo prazo deste grupo, e realizar atividades que promovam empoderamento de seus cooperados, de forma que a participação de todos facilite com que as tarefas administrativas e ações decisórias não se limitem às pessoas da diretoria, o que é bastante comum no modelo hegemônico existente em nossa 
sociedade hierarquizada e de organizações baseadas na heterogestão - gestão realizada pelo outro, ou seja, há uma hierarquia na tomada de decisões, na escolha das ações a serem executadas e no nível de informação que cada indivíduo recebe [13].

Os resultados podem ser enunciados, em termos de relacionamentos interpessoais e resultados financeiros concretos: busca de fontes alternativas de financiamento para construção de uma nova central de triagem; maior poder de negociação e diálogo frente às instâncias públicas; realização de reuniões para ouvir seus membros e trocar informações entre a diretoria e cooperados; e aumento da renda mensal distribuída. Continuam os desafios de ampliar a participação de todos os cooperados no processo decisório, de lutar por uma política pública municipal que ofereça apoios importantes para o desenvolvimento desta cooperativa, diálogo e convergência de interesses e objetivos entre os apoiadores. Neste contexto, com certeza, a incubação feita de maneira próxima e aberta às necessidades do grupo, mostra-se de relevância fundamental.

No que diz respeito à Rede Monte Alegre o pressuposto para esse trabalho é que o desenvolvimento local pode ser alcançado via estímulo à formação de redes entre empreendimentos solidários, através de seu fortalecimento mútuo e de sua atuação em prol da comunidade [7].

Sendo assim, o trabalho desempenhado tem sido a formação de um grupo de capacitação e incentivo ao empreendedorismo, cooperação, trocas constantes de experiência, formação de parcerias e criação de ambiente favorável a novos empreendimentos, entre outros. Semanalmente uma reunião é realizada, com temas que tangem à economia solidária e a gestão de empreendimentos, de maneira a envolver o grupo em uma mesma sintonia rumo à realização segura de seus projetos de geração de renda.

Em todos os momentos, é incentivada a palavra de ordem clichê que o próprio grupo compreendeu traduzir seu propósito: “A união faz a força”. Apesar de estar em seu início, com dois meses de trabalho, e com dificuldades para envolver de maneira comprometida e assídua todos os membros que participaram das reuniões (em torno de 25 pessoas em reuniões distintas), o grupo vem se mostrando relevante para os participantes e para a associação, já que o objetivo de todos é alinhar o crescimento individual com o desenvolvimento da comunidade.

As ações referentes ao Projeto Talentos têm procurado apoiar a organização da produção, no sentido de pensar conjuntamente nas melhores estratégias de produção, escalas de trabalho, tipos de produtos produzidos, materiais utilizados, entre outros. Em relação à comercialização, o objetivo é apresentar canais de comercialização diversos, refletindo sobre aspectos positivos e negativos de cada um. Em relação à dinâmica do grupo, o objetivo seria o de empoderar as participantes do mesmo, para que no futuro elas estivessem capacitadas para tomar as próprias decisões e coordenar, coletivamente, este empreendimento. A etapa inicial de grande importância à dinâmica do grupo foi a elaboração de um regimento interno, sendo esse alterado ao longo do tempo segundo as experiências e adesão do próprio grupo.

No momento atual, o foco de ação da incubadora está sendo a pesquisa de canais de comercialização, bem como a organização da produção. $\mathrm{O}$ empoderamento do 
grupo como todo e de cada membro participante dele é trabalhado desde o início, mas é sendo entendido como um processo contínuo feito através da formação do grupo em economia solidária, dinâmicas grupais e conversas que busquem trazer todos os membros do Projeto Talentos para a liderança.

No Projeto Aquífero até o momento, a principal questão alinhada entre as duas partes é a participação da incubadora no grupo de trabalho de comercialização que ainda ocorre de forma incipiente, principalmente porque depende do prazo necessário para a produção, já que o sistema agroflorestal exige um tempo de preparação e desenvolvimento do solo.

As ações têm sido especificamente na busca por orçamentos, cotações de preços para materiais de comunicação (conforme edital do governo federal), descoberta de mecanismos e formas de divulgação para o público-alvo.

No CAPS $\mathrm{AD}$, neste momento um grupo de seis usuários mostrou-se interessado, de fato, na proposta. Assim, já com o grupo formado, começaram a discussão e experimentação de atividades, com base no histórico de ocupações dos usuários, com objetivo final de definir qual seria o ofício do grupo. No início, os usuários selecionaram algumas atividades artesanais para experimentação. No entanto, após a realização de alguns grupos de atividades, os usuários refletiram sobre o trabalho que realmente gostariam de realizar, sendo decidido por uma cooperativa de serviços, já que muitos tinham experiências anteriores na área de construção civil, jardinagem, pintura, entre outros.

A metodologia de incubação seguida com este grupo segue uma abordagem participativa, através de dinâmicas de grupo, discussão de temas relevantes ao fortalecimento da coesão grupal e funcionamento de práticas de geração de renda e trabalho segundo a economia solidária tais como: práticas autogestionárias nas relações de trabalho, valores e atitudes grupais e interpessoais apoiadas na cooperação, no apoio mútuo frente às recaídas e crises psicossociais vivenciadas e características dos integrantes do grupo incubado, pois são pessoas em uso prejudicial de substâncias psicoativas, portanto incentiva-se a criação de um sistema de suporte social recíproco frente às recaídas e crises, sem reproduzir práticas reacionárias e punitivas, típicas das relações de trabalho e modo de produção capitalista. Da mesma forma, busca-se o desenvolvimento de atitudes de responsabilidade para com o grupo, necessárias à produção de coesão, autonomia e liberdade do grupo.

Portanto, acredita-se que, com base nas experiências de incubação e fomento a empreendimentos solidários de geração de renda e redes sociais de suporte, ainda embrionárias, mas com demonstrativos exitosos, a Co-Labora vem contribuindo efetivamente para a redução da vulnerabilidade social de parcelas da população, para a redução das injustiças e iniquidades vividas por estes grupos e para a elaboração de metodologias de enfrentamento à pobreza no país.

Atualmente está sendo elaborado um projeto de captação de recursos para compra de materiais para que os usuários possam começar a prestação de serviços. Concomitante a isso, ainda está sendo finalizado o regimento interno, que ao longo das reuniões foi sofrendo algumas alterações. 
Percebe-se uma mudança constante que alcança não apenas a situação do grupo, transcendendo para a vida do sujeito. Com a possibilidade de geração de renda, o indivíduo se sente mais respeitado, mais forte e empoderado para se relacionar com a sociedade em que vive. A autogestão possibilita que eles assumam responsabilidades e se sintam igualmente importantes em determinada situação, o que favorece a autoestima. Eles passam a refletir mais sobre o que querem do trabalho, da vida, o que esperam da sociedade, da comunidade em que vivem, passando a dispor de cidadania, por vezes camuflada frente às tantas desigualdades sociais. De forma geral, isso tem causado um impacto na comunidade circundante aos grupos, já que esses indivíduos são parte de um todo, e à medida que mudam, levam a mudança para o coletivo. Percebe-se um grande sentimento de solidariedade deles em relação à comunidade, uma vez que se veem na responsabilidade de compartilhar os conhecimentos adquiridos, de envolver toda a comunidade nesse sentimento de poder, de decisão, de reflexão, de expectativa de mudança. Assim, essa transformação acontece em cadeia, começando um a um no próprio grupo incubado, passando desses para os mais próximos a eles, e assim por diante.

\section{CONSIDERAÇÕES FINAIS}

A vulnerabilidade social de populações mundiais tem seu aumento com o declínio dos Estados de Bem Estar Social, e a ascensão da orientação econômico-política neoliberal, a partir da qual se assiste ao fim dos sistemas de proteção social, que se pretendiam, por meio de estratégias negociadas entre os polos sociais interessados, levar a aceitarem objetivos sensatos e compromissos mútuos que garantissem a estabilidade do sistema social através de políticas sociais distributivas e manutenção das relações de trabalho estáveis. Porém, com o neoliberalismo a seguridade social é deixada de ser tarefa do Estado e a crise dos Estados-Providência é representada pela crise da solidariedade, da coesão social, ampliada pela transformação das relações entre a economia e a sociedade (a crise do trabalho) e dos modos de constituição das identidades individuais e coletivas $[3,14]$.

No Brasil, a persistência de grupos e pessoas em exclusão social e pobreza em determinados territórios eleva os índices de vulnerabilidade social, com exclusão ou difícil acesso desses sujeitos aos serviços e equipamentos públicos, aos bens materiais e imateriais, e a oportunidades que permitem a reprodução da vida em um patamar de dignidade. A exclusão ou o difícil acesso à renda, trabalho, educação, habitação, transporte e mobilidade, cultura, lazer, meio ambiente sustentável e a redes de suporte social leva a persistirem iniquidades sociais em nível dos territórios periféricos urbanos, localidades geográficas e culturais distantes dos centros urbanos de grandes e médias cidades brasileiras [9]. 
O debate em relação à pobreza no Brasil está longe de ser esgotado, movido pela perturbação e o desconforto com os elevados índices de desigualdade social, esse debate passa a mobilizar cada vez mais a arena pública para a complexa discussão acerca dos horizontes e das políticas de combate à desigualdade e à pobreza no país [4]. Neste sentido, estratégias de enfrentamento à vulnerabilidade social e erradicação da pobreza apresentam-se como relevantes e necessários.

Segundo Singer[13], o cooperativismo, na filosofia da economia solidária, constitui-se como resposta ao desemprego e à exclusão social e à crise das formas tradicionais do trabalho a partir da mundialização da economia capitalista. Temos então, que o movimento de economia solidária tem abrangência mundial. No contexto brasileiro, um marco importante do reconhecimento político da economia solidaria e o inicio de políticas publicas nesta direção, é a criação do Fórum Brasileiro de Economia Solidária (FBES) e da Secretaria Nacional de Economia Solidária (SENAES), que ocorreram em 2003. Desde então se verificou avanços nas políticas setoriais, a exemplo dos setores que discutem trabalho e renda, desenvolvimento social, desenvolvimento territorial, entre outros. Um exemplo das ações atuais do SENAES é a implementação do Programa Economia Solidária em Desenvolvimento, cujo objetivo é o fortalecimento e a divulgação da economia solidária. Avanços também ocorrem nas esferas estaduais e municipais. Exemplos de iniciativas criadas são os bancos do povo, empreendedorismo popular solidário, capacitação, e centros populares de comercialização $[1,2]$.

Um dos frutos dessa política foi a realização da I Conferencia Nacional de Economia Solidária (CONAES) em 2006 e a II Conferência em 2010, concretizando a participação dos segmentos envolvidos, desde o nível municipal, estadual e federal. A III Conferência está sendo organizada.

Considerando a relevância nacional que a economia solidária possui, a incubadora Co-Labora compreende a importância da sua inserção no movimento nacional. Assim, é membro da Rede Sudeste de incubadoras universitárias de cooperativas populares, e com vistas à participação na Rede Nacional. Por outro lado entendendo o seu papel em nível municipal, a incubadora Co-Labora participa da organização do Fórum Municipal de Economia Solidária, com propósito de criar espaços de articulação entre vários empreendimentos solidários, discutindo potencialidades, desafios e propostas para fortalecimento da economia solidaria no município e região.

Enquanto um projeto acadêmico busca-se a articulação entre ensino, pesquisa e extensão, para que o conhecimento gerado possa trazer contribuições para a sociedade, além da formação para graduandos, pós-graduandos, docentes e demais profissionais. Nesse sentido, a Co-Labora ITES tem colocado-se como impulsionadora dessa filosofia e, ao apoiar essas iniciativas, vem contribuindo efetivamente para enfatizar a solidariedade como um fundamento ético que orienta a formação de redes para inclusão social pelo trabalho, implicando em responsabilidade social e conciliação de interesses comunitários por meio da participação de atores e organizações sociais e da incubação de iniciativas de empreendimentos solidários dentro das finalidades da busca de enfrentamento à vulnerabilidade social e geração de renda e oportunidades 
em nível dos territórios.

\section{REFERÊNCIAS}

[1] BRASIL. Secretaria Nacional de Economia Solidária. Disponível em: <http://portal.mte.gov.br/ecosolidaria/a-economia-solidaria/>. Acesso em 23/09/2014.

[2] II CONAES - Conferência Nacional de Economia Solidária: Pelo direito de produzir e viver em cooperação de maneira sustentável. Documento Final. Brasília, 2010. Disponível em: <http://portal.mte.gov.br/data/files/8A7C8 ${ }_{12} \mathrm{D}_{3} 6 \mathrm{~A} 28000013731 \mathrm{C} 8 \mathrm{C}_{25} \mathrm{D} 7 \mathrm{CEE} / \mathrm{II}$ _coanes_documento_final.pdf $>$. Acesso em 23 set 2014 .

[3] DOMINGUES, L.H. Políticas sociais em mudança: o Estado, as empresas, e a intervenção social. Lisboa: Universidade Técnica de Lisboa. Instituto Superior de Ciências Sociais e Políticas, 2005.

[4] HENRIQUES, R. Desnaturalizar a desigualdade e erradicar a pobreza no Brasil. In: NOLETO, MJ; WERTHEIN, J (Orgs). Desigualdade e pobreza no Brasil: traçando caminhos para a inclusão social. Brasília: UNESCO, 2003.

[5] IBGE. Censo Demográfico. Fundação Seade, 2000.

[6] IBGE. Dados do PIB. 2013. Disponível em: <http://www.ibge.gov.br/home/ estatistica/pesquisas/resultado.php? consulta $=$ pib $>$

[7] MEDEIROS, A.C.; CUNHA, E.V., MATOS, M. M. de. Economia Solidária e Desenvolvimento Local: A Prática dos Empreendimentos Econômicos e Solidários na Região do Cariri Cearense. VI Encontro Nacional de Pesquisadores em Gestão Social - ENAPEGS. São Paulo, 2012.

[8] MTE. Cadastro dos empreendimentos econômicos solidários. 2006. Disponível em: <http://portal.mte.gov.br/ecosolidaria/ cadastro-nacional-de-empreendimentos-economicos-solidarios/ $>$.

[9] SAWAIA, B. As artimanhas da exclusão: análise psicossocial e ética da desigualdade social. Petrópolis: Vozes, 2007.

[10] SEADE, Fundação. Índice paulista de vulnerabilidade social. 2013. Disponível em: <http://www.seade.gov.br/ indice-paulista-de-vulnerabilidade-social-ipvs-versao-2010/>

[11] SENAES. Apresentação SENAES. 2013. Disponível em: <http://portal.mte. gov.br/ecosolidaria/secretaria-nacional-de-economia-solidaria/>

[12] SILVA, R.C. Metodologias participativas para trabalhos de promoção de saúde e cidadania. São Paulo: Vetor, 2002.

[13] SINGER, P. Introdução à Economia Solidária. São Paulo: Fundação Perseu Abramo, 2002.

[14] SORJ, B.; MARTUCCELLI, D. O desafio latino-americano: coesão social e democracia. Rio de Janeiro: Civilização Brasileira, 2008. 
PERLA CALIL PONGELUPPE WADHY REBEHY docente da Faculdade de Economia, Administração e Contabilidade de Ribeirão Preto da Universidade de São Paulo (FEARP-USP) e coordenadora da Co-LaboraITES - perla@usp.br

DANIEL YACOUB BELLISSIMO bolsista DTI-C do CNPq para atuação como supervisor na Co-Labora ITES e mestrando na Faculdade de Economia, Administração e Contabilidade de Ribeirão Preto da Universidade de São Paulo (FEARP-USP)

SAMANTHA GORDO SANDRIN bolsista DTI-C do CNPq para atuação como supervisora na Co-Labora ITES e graduada em Terapia Ocupacional pela Faculdade de Medicina de Ribeirão Preto da Universidade de São Paulo (FMRP-USP)

REGINA CÉLIA FIORATI docente da Faculdade de Medicina de Ribeirão Preto da Universidade de São Paulo (FMRP-USP) e professora membro da Co-Labora ITES

REGINA YONEKO DAKUZAKU CARRETTA docente da Faculdade de Medicina de Ribeirão Preto da Universidade de São Paulo (FMRP-USP) e professora membro da Co-Labora ITES 